\title{
A LÍRICA EXISTENCIALISTA DE ROBERVAL PEREYR EM “MIRANTES”
}

\author{
Roseni Miranda da Silva Nascimento ${ }^{\mathbf{1}}$, Luiz Antonio de Carvalho Valverde ${ }^{2}$ \\ 1. graduanda em Licenciatura em Letras Vernáculas, Universidade Estadual de Feira de Santana, e-mail: \\ rosesilvanascimento2014@gmail.com \\ 2.Orientador, Departamento de Letras e Artes, Universidade Estadual de Feira de Santana, e-mail: lacvalverde@uol.com.br
}

PALAVRAS-CHAVE: Roberval Pereyr; Poesia contemporânea; Existencialismo

\section{INTRODUÇÃO}

No presente trabalho, proponho a análise e reflexões dos poemas "Lírico; O outro no espelho; Ofício e Poema", do livro Mirantes (2011), ganhador do prémio Braskem de literatura (promovido pela Academia de Letras da Bahia) do poeta feirense Roberval Pereyr. É escritor, compositor, professor universitário e co- fundador da revista feirense Hera (1972/2005), de Feira de Santana. Entre seus livros destacam-se: As roupas do nu (coleção dos Novos, em 1981); Ocidentais (1987); Saguão de mitos (1998); A unidade primordial da lírica moderna (2000); Amálgama- Nas praias do avesso e poesia anterior (2004). No livro Mirantes, encontramos um lirismo que vem desde os cancioneiros até os grandes líricos da poesia moderna do século XX. As suas poesias possuem características marcantes do existencialismo e da metafísica. Em seus poemas notamos a busca pelo sentido do ser e propõe refletir o lugar do ser no mundo. Tomaremos, como referencial teórico autores como Octavio Paz e Hugo Friedrich, no que diz respeito às características da lírica moderna, e as ideias de pensadores como Sartre e Kierkegaard, no que se refere ao pensamento existencialista, que coloca o homem diante da sua condição existencial, enfrentando o mundo, a angústia frente à sua finitude.

\section{MATERIAL E MÉTODOS OU METODOLOGIA (ou equivalente)}

O método utilizado neste artigo foi a análise e reflexão de quatro poemas do livro Mirantes, assim permitindo estabelecer relações entre sistemas análogos, evidenciando o que há em comum entre eles.

A intertextualidade entre os poemas de Roberval Pereyr analisados foi estabelecida por um enfoque estético-filosófico, priorizando-se a filosofia existencialista sartreana, e as ideias de pensadores como Octavio Paz e Hugo Friedrich, no que diz respeito às características da lírica moderna.

\section{RESULTADOS E/OU DISCUSSÃO (ou Análise e discussão dos resultados) ANÁLISE DE POEMAS}

Neste artigo utilizam-se quatro poemas de Roberval Pereyr, Lírico; O outro no espelho; Ofício e Poema como objeto de análise deste estudo.

\section{LÍRICO}

$\mathrm{Na}$ selva de meus dilemas tratei com feras: palavras. 
na alma, que é mãe de éguas.

E perscrutei sob trevas

a nova era e seus mapas:

abri veredas e rotas

às feras que eu libertava.

Ó selvas de meus dilemas

ó éguas da alma, bravas.

O eu lírico, em todos os poemas, se vê diante de uma busca pelo sentido do ser, refletindo sobre sua existência.

A intertextualidade consiste em um diálogo entre textos. No caso da poesia, a intertextualidade aparece como elemento reforçador de uma ideia. O poema "Lírico", de Roberval Pereyr, mantém um forte diálogo com o poema "O Lutador", de Carlos Drummond de Andrade, ambos metapoéticos. Pereyr fala da labuta do poeta com as palavras. De novo, surge a imagem de um equino, mas dessa vez como símbolo da palavra no poema, "fera" a ser domada pelo poeta. Conforme o poeta vai arranjando as palavras, abrindo "veredas e rotas", as feras, palavras, vão sendo libertadas. Também Drummond falou da sua luta com as palavras:

Lutar com palavras é a luta mais vã. Entanto lutamos mal rompe a manhã. (ANDRADE, 2012, p.215)

A intertextualidade se encontra na imagem construída para as palavras. Para ambos, elas são como animais bravios que precisam ser domados. Pereyr diz que as palavras são como éguas bravas da alma; Drummond, que há algumas fortes como um javali. Em todo o poema, o poeta usa de metáforas para expressar o poder e a intenção da palavra em meio aos seus dilemas vivenciados interiormente pelo seu ser. A palavra é vista como aquela que é capaz de amar e ferir, matar e salvar. Segundo $P A Z$, "A palavra é o próprio homem. Somos feitos de palavra. “(PAZ, Octávio. p.37).

\section{O OUTRO NO ESPELHO}

O que dói em mim, irmão, sou eu mesmo.

Eu, que arremato em meu ser tantos erros.

Eu, medo máximo que sonha e que canta:

não é dúvida o que trago

- é ciência engasgada;

língua cheia de espanto, 
mãos distantes da alma.

3. OFÍCIO

Vivo de raptos. Cactos

florescem no meu umbigo.

Predador de mim mesmo, persigo-me nos ermos

do sem- sentido.

\section{POEMA}

No meu limite sou nada.

Nenhuma estrada termina.

Andar é adiar a sina, tornando infinda a estrada.

E não me peço consolo. Ao mundo, nenhum ensino. Vou decompor meu destino, negando as regras do jogo.

Mas ao negá-las, me iludo: negar é seguir negando. Finito, mas caminhando, No teu limite sou tudo.

$\mathrm{O}$ existencialismo sartreano defende que o homem possui a liberdade. Somente o homem se constrói através de s.uas escolhas. Sendo assim, somente o homem é responsável por suas escolhas e ações. Podemos observar isto no $2^{\circ}$ poema: "O que dó $i$ em mim, irmão, sou eu mesmo. Eu, que arremato em meu ser tantos erros. (p.26). Este $2^{\circ}$ poema faz uma reflexão do eu e nele está presente características dualistas em todo o poema, a começar pelo título (O OUTRO NO ESPELHO), no qual é revelado a dualidade na construção do ser, ao suscitar uma outra pessoa ou personagem por trás de um espelho, e concretizando ações no decorrer do poema, reafirmando a ideia que fundamenta o existencialismo sartreano, o homem nada mais é do que aquilo que ele se faz (SARTRE, 1970, p.6).

No $3^{\circ}$ poema, "Vivo de raptos, ... Predador de mim mesmo, ... persigo-me nos ermos do sem- sentido. “ (p.65), o eu lírico é vítima do pessimismo, sente-se miserável, dotado de células sombrias por tais antagonismos propícios a sua espécie, caracterizando uma antinomia para a sociedade, razão pela qual o ser se sente só, entregue ao nada. O poema é fortemente interiorizado na expressão: "A palavra é uma ponte através da qual o homem tenta superar a distância que o separa da realidade exterior. " (PAZ, Octávio p.43). 
E no $4^{\circ}$ poema, o texto é composto por três estrofes com quatro versos poéticos cada. A diferenciação se dá no uso das rimas, e as rimas estão a serviço da temática do texto É notória a anulação de atitudes do ser humano a objetos que são definidos pela sua essência (consolo, ensino, destino, jogo) na segunda estrofe: “E não me peço consolo. Ao mundo, nenhum ensino. Vou decompor meu destino, negando as regras do jogo." (p.35). Ou seja, o eu lírico se sente condenado a não lutar contra padrões e a estereótipos acerca de sua existência, observados na primeira e terceira estrofe.

Observa-se também que a ação de um homem influencia a coletividade, segundo Sartre, no primeiro e último verso da primeira e terceira estrofe respectivamente: "No meu limite sou nada; No teu limite sou tudo. " (p.35).

Ler esses poemas pela filosofia existencialista sartreana revela a riqueza da poética brasileira e a preocupação e compreensão acerca da reflexão sobre a existência a partir da supremacia humana.

\section{CONSIDERAÇÕES FINAIS (ou Conclusão)}

$\mathrm{O}$ trabalho apresentado nos permitiu fazer um pequeno percurso pelos poemas do poeta feirense Roberval Pereyr e identificar um lirismo denso que envolve a sua trajetória como um artista da contemporaneidade. Atentando principalmente para o seu livro Mirantes, buscamos neste trabalho identificar de que forma o sujeito lírico se comporta ao longo da sua poética, em especial nos poemas: Lírico, $\mathrm{O}$ outro no espelho, Ofício e Poema. Para isso, apontamos determinados aspectos da vida do poeta que nos ajudassem a entender um pouco do seu processo criativo, como por exemplo, a busca de uma poesia de essências.

Por fim, apoiados em alguns pressupostos teóricos, pudemos adentrar nos poemas de Roberval Pereyr para identificarmos as diferentes nuances dos sujeitos líricos em seus textos. Vale frisar, porém, que muitas são as teorias, tanto no campo da filosofia quanto nos estudos da poética e os conceitos são amplos. Buscamos neste trabalho, fazer uma leitura teórica e crítica dos poemas acima citados, e mesmo recorrendo a alguns conceitos históricos, procuramos, acima de tudo, compreender o texto poético.

Esperamos, pelo apresentado neste trabalho, ter contribuído para o conhecimento da obra de Roberval Pereyr e, em última instância, ter acrescentado um novo olhar sobre o livro Mirantes, em especial os poemas estudados, no que diz respeito à prevalência de traços da estética existencialista.

\section{REFERÊNCIAS}

PAZ, Octávio. O Arco e a lira/ Octávio Paz; tradução de Olga Savary. -Rio de Janeiro: Nova Fronteira, 1982. (Coleção Logos)

FRIEDRICH, H. A estrutura da lírica moderna: da metade do século XIX a meados do século XX. Tradução de Marise M. Curioni. São Paulo: Duas cidades, 1978.

A unidade primordial da lírica moderna. Feira de Santana: UEFS, 2000.

SARTE, J.P. O Existencialismo é um humanismo. Trad. Rita Correia Guedes. São

Paulo: Nova Cultural, 1987. $3^{\mathrm{a}} \mathrm{ed}$.

MOUTINHO, L. D. S. Sartre existencialismo e liberdade. São Paulo: Moderna, 1995. Mirantes/ Roberval Pereyr. - Rio de Janeiro: 7Letras, 2012. 108p.: $21 \mathrm{c}$

ANJOS. A. Eu e outras poesias. São Paulo: Martin Claret, 2005. 
ANDRADE, Carlos Drummond de. Antologia poética. São Paulo: Companhia das Letras, 2012. 